\title{
Influence of processing on the ethylene-vinyl alcohol (EVOH) properties: Application of the successive self-nucleation and annealing (SSA) technique
}

\author{
E. Franco-Urquiza*, O. O. Santana, J. Gámez-Pérez, A. B. Martínez, M. Ll. Maspoch \\ Centre Català del Plàstic, Universitat Politècnica de Catalunya (UPC), Colom 114, 08222 Terrassa, Spain
}

Received 8 October 2009; accepted in revised form 22 December 2009

\begin{abstract}
Films of EVOH copolymers, processed three times by twin-screw extrusion were prepared using a cast-film line. The variation on the melt flow rate (MFR) and rheological behaviour of the films were determined, as well as the thermal properties assessed by differential scanning calorimetry (DSC) and dynamic-mechanical thermal analysis (DMTA). As the results showed that the reprocessing induced an increase in the viscosity and orientation of the films, it was suggested that structural modifications from chain-extension or cross-linking reactions promoted by hydroxyl and residual acetoxyl groups, could be occurring. The successive self-nucleation and annealing (SSA) technique was applied, evidencing the structural modifications on the EVOH copolymer.
\end{abstract}

Keywords: processing technologies, EVOH, SSA, processing-structure relationship

\section{Introduction}

Ethylene-vinyl alcohol (EVOH) copolymers are semicrystalline materials regardless of vinyl alcohol ( $\mathrm{VOH})$ content. They are prepared commercially by transesterification (saponification) of Ethylene-vinyl acetate copolymers (EVA). They could be considered, then, as complex copolymers of ethylene, vinyl alcohol and some vinyl acetate units, if the saponification process is not $100 \%$ complete [1-3]. In addition, owing to the free-radical nature of the EVA copolymerization, the resulting EVOH copolymers posses a certain degree of short chain branching, which, according to Vanderhart et al. [4] are rejected from the crystalline region.

EVOH copolymers are widely employed in food packaging, biomedical and pharmaceutical industries because of their excellent barrier properties to gases, hydrocarbons and organic solvents [3, 5]. Such properties are caused by strong hydrogen bond interactions, both inter and intra-molecular, which reduce the free volume of the polymer chains [6]. However, the barrier properties, stiffness or tensile strength, drop dramatically in high relative humidity conditions. EVOH copolymers are highly hygroscopic, as a consequence of the hydrophilic $\mathrm{OH}$ side groups and their interaction with the absorbed water molecules weakens the inter- and intra-molecular hydrogen bonds, increasing the free volume of the chains $[7,8]$. To avoid that loss of the barrier capacity, some authors have proposed the addition of organo-modified clays into the EVOH matrix via melt-blending method, using internal mixers and twin-screw extrusion $[9,10]$. Some authors [11-13] suggested a melt-blending process for preparation of thermoplastic/organomodified clays that could be easily scaled to industrial level. Such process implies three steps of twin-screw extrusion: (a) preparation of a masterbatch with high clay content ( $10 \mathrm{wt} \%$ ), (b) master- 
batch homogenization and (c) final dilution to the required clay contents.

The global aim of this work is to analyze the possible structural and properties modifications of EVOH occurred during a 3-step twin-screw extrusion process during its melt-blending with organomodified clay. In this paper it will be discussed and analysed by the use of the thermal fractionation technique known as successive self-nucleation and annealing (SSA) and relate those results with structural changes suggested by other techniques (plateplate rheometer, dynamo mechanical thermal analysis and differential scanning calorimetry).

The SSA fractionation technique, proposed by Müller et al. 14], is based on the existence of defects in the main polymer chain, which limits the segment length able to crystallize, contributing to the generation of a crystalline distribution with different lamellar thicknesses during crystallization. The method involves applying a thermal treatment that includes intercalated isothermal steps, which promote the nucleation and annealing of crystals. A final standard heating scan reveals the succession of endothermic signals corresponding to the melting of each crystalline entity [15].

Müller et al. [14] analyzed the branching distribution from linear low-density polyethylene (LLDPE), pointing out that the melting enthalpy of each signal can be considered proportional to the normalized weight fraction of molecular populations with a certain branching content. The SSA technique has also been successfully applied in the characterization of several polymer systems [16], as for example on functionalized polyethylenes [17].

\section{Experimental}

\subsection{Materials}

EVOH copolymer (Soarnol ${ }^{\circledR}$ DC3203F) containing $32 \mathrm{~mol} \%$ ethylene (E32) was kindly supplied by Nippon Gohsei (Osaka, Japan). The melting point $\left(T_{m}\right)$ and glass transition $\left(T_{g}\right)$ temperatures are 183 and $69^{\circ} \mathrm{C}$ respectively.

\subsection{Melt processing and films preparation}

Films of $300 \mu \mathrm{m}$ thickness were obtained using a cast film line, consisting of a single-screw extruder $(L / D=25 ; D=20 \mathrm{~mm})$ Collin Teach Line 20T-E (Ebersberg, Germany), a multi-manifold die and chill-rolls calender Teach Line CR 72T (Ebersberg, Germany). The profile temperatures used were those suggested by the $\mathrm{E} 32$ producer, $160^{\circ} \mathrm{C}$ in feed section to $220^{\circ} \mathrm{C}$ at the extrusion die and the chillrolls were set at $50^{\circ} \mathrm{C}$ with 7 bar of pressure.

In order to simulate the production of $\mathrm{EVOH} / \mathrm{clay}$ nanocomposites, E32 was processed several times $(1,2$ or 3$)$ in a twin-screw extruder $(L / D=36 ; D=$ $25 \mathrm{~mm}$ ) Collin ZK-35 (Ebersberg, Germany) before the film production. In every reprocessing step, the twin-screw rotation speed was set at $80 \mathrm{rpm}$ and the processing temperatures were comprised between $160^{\circ} \mathrm{C}$ in the feed section and $220^{\circ} \mathrm{C}$ at the extrusion die. According to the processing history, the films were named as follows: E32-0X for the film non-processed by twin-screw extruder and E32-1X, $2 \mathrm{X}$ or $3 \mathrm{X}$ for the films processed in twin-screw extruder 1,2 or 3 times, respectively.

It is important to mention that E32 was dried (in pellet form) at $110^{\circ} \mathrm{C}$ during $10 \mathrm{~h}$ in an air oven J. P. Selecta (Barcelona, Spain) before each twinscrew extrusion and cast film processes, since the presence of coordinated water, along with shear stress and temperature processing, may lead to significant modifications in the chemical structure of EVOH.

\subsection{Characterization techniques}

Melt flow rate was determined using a melt flow tester CEAST 6841 (Pianezza, Italy) at $210^{\circ} \mathrm{C}$ and a load of $2.16 \mathrm{~kg}$, according to the ISO 1133 standard.

Rheological tests were performed in a dynamic rheometer AR-G2 from TA Instrument (New Castle, USA) with $25 \mathrm{~mm}$ diameter parallel plates and a gap of $300 \mu \mathrm{m}$ approximately. The tests were run at a frequency rate from 0.1 to $100 \mathrm{~Hz}, 220^{\circ} \mathrm{C}$ and $2 \%$ strain amplitude to ensure that measurements were taken within the linear viscoelastic range. All experiments were conducted under nitrogen gas blanket in order to prevent thermo-oxidative degradation during the test. The apparent shear viscosity $\left(\eta_{\text {app }}\right)$ vs. shear rate $(\dot{\gamma})$ curves were generated using the Cox-Merz rule and the data were adjusted using the Cross model.

Dynamic mechanical thermal analysis (DMTA) measurements in tensile mode were performed using a DMTA Q800 from TA Instruments (New 
Castle, USA). The tests were run in a temperature range from 25 to $160^{\circ} \mathrm{C}$ under linear viscoelastic conditions applying a static stress of $1 \mathrm{MPa}$ with a frequency of $1 \mathrm{~Hz}$ and a constant heating rate of $2{ }^{\circ} \mathrm{C} / \mathrm{min}$. In order to prevent sample buckling during heating, the 'force track' option was activated and set at $120 \%$ with an initial pre-load of $0.5 \mathrm{~N}$. All rectangular samples $(15 \times 5 \times 0.3 \mathrm{~mm})$ were taken from central part of the films in the melt flow direction.

Differential scanning calorimetry (DSC) measurements were carried out using a Perkin-Elmer Pyris 1 calorimeter (Massachusetts, USA) with a cooling system Intracooler IIP. The calorimeter was previously calibrated with standard samples of Indium and Lead. The samples were taken form the central zone of the films with exactly $10 \mathrm{mg}$ in weight and the scans were run under nitrogen atmosphere using aluminium pans.

Two different thermal experiments were performed: the first one consisted in a standard evaluation, with a first heating scan (from 30 to $230^{\circ} \mathrm{C}$ with an isothermal step of $3 \mathrm{~min}$ ), cooling scan (including an isothermal step) and subsequent second heating scan. All runs were conducted at a heating/cooling rate of $10^{\circ} \mathrm{C} / \mathrm{min}$. The second approach consisted in applying the successive selfnucleation and annealing (SSA) method, according to the thermal program sketched in Figure 1. After erasing the thermal history and setting a common controlled cooling at $10^{\circ} \mathrm{C} / \mathrm{min}$ (ramp A, in Figure 1), five cycles of heating-cooling scans with isothermal steps of $5 \mathrm{~min}$ were run, decreasing the isothermal temperature $\left(T_{s 1}\right)$ in each cycle. Finally,

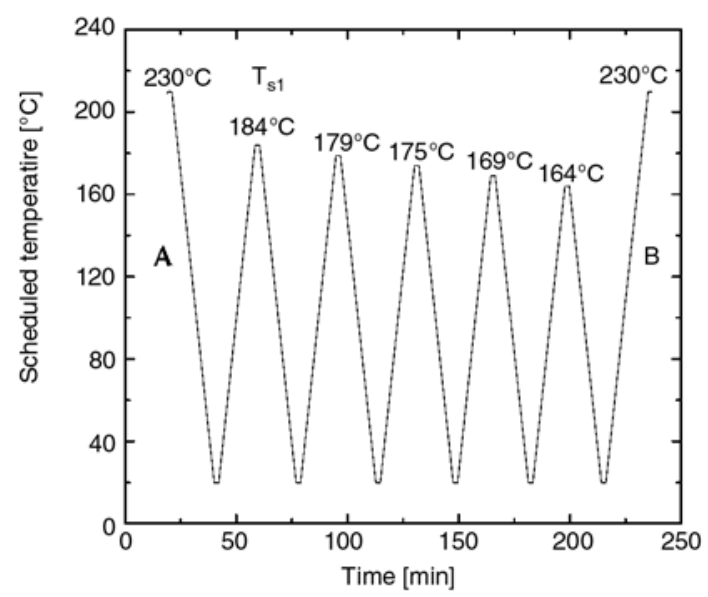

Figure 1. Schematic representation of successive selfnucleation and annealing (SSA) thermal treatment a heating scan (ramp B in Figure 1) was performed in order to reveal the melting behaviour of the treated samples.

The initial isothermal temperature $T_{s 1}=184^{\circ} \mathrm{C}$, selected as the optimum self-nucleation temperature (Figure 1), was determined by self-nucleation tests performed according to the methodology suggested by Fillon et al. [18]. This temperature caused the maximum shift on the peak crystallization temperature $\left(T_{c}\right)$ without annealing. The subsequent temperatures $\left(179\right.$ to $\left.164^{\circ} \mathrm{C}\right)$ were selected at intervals of $5^{\circ} \mathrm{C}$ lower than the previous $T_{s}$ (Figure 1), following the program suggested for polyethylene based systems [14].

The melting $\left(T_{m}\right)$ and crystallization $\left(T_{c}\right)$ temperatures, as well as enthalpies related to the corresponding signals, were obtained according to standards procedures. In order to estimate the crystallinity degree $\left(X_{c}\right)$, the enthalpy of a $100 \%$ pure crystalline poly-vinyl alcohol (157.8 J/g) has been taken [8]. According to Cerrada et al. [8], EVOH copolymers show a polymorphic behaviour depending on composition and thermal treatment. Nevertheless, with relative high vinyl alcohol content, the $\mathrm{EVOH}$ copolymers crystallize into a monoclinic lattice, similar to that of poly-vinyl alcohol, regardless of the ethylene sequences, which are located as punctual defects into the main crystalline lattice.

\section{Results and discussion}

\subsection{Melt flow rate and rheological measurements}

The variations on the melt flow rate (MFR) with respect to the number of twin-screw extrusion steps is shown in Figure 2a. It can be observed that the MFR decreases up to $26 \%$ from the E32-0X as the number of extrusion steps increases. Such a fall in MFR values lead to perform a detailed study of the rheological behaviour with a plate-plate rheometer. The curves of apparent shear viscosity $\left(\eta_{a p p}\right)$ versus shear rate $(\dot{\gamma})$ obtained after applying the Cox-Merz rule, are plotted in Figure $2 b$.

From the rheological measurements, it can be noticed an increase of the zero shear viscosity $\left(\eta_{0}\right)$ as well as a decrease on $\dot{\gamma}$ at the beginning of the pseudoplastic behaviour. This implied an increase on the characteristic time $(k)$, as reported in Table 1, where the main rheological parameters for all materials are summarized. 

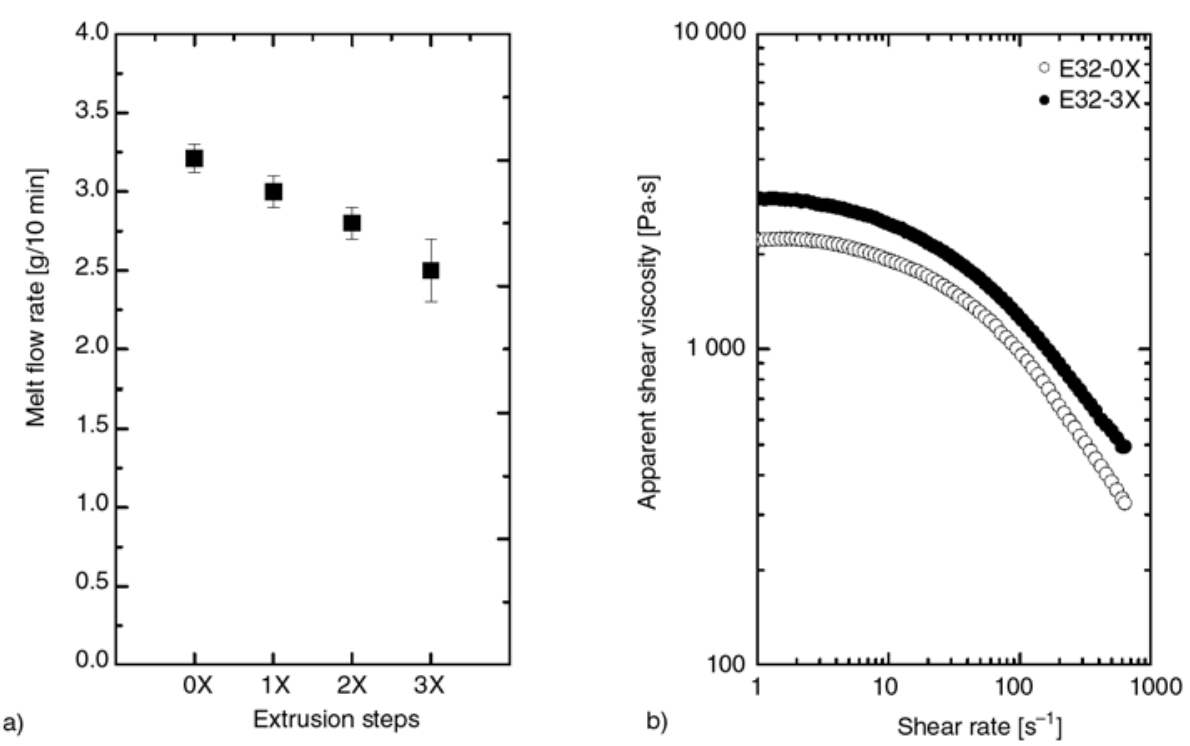

Figure 2. a) Melt flow rate variation for each extrusion step and b) apparent shear viscosity related to shear rate

Table 1. Rheological parameters based on the Cross equation

\begin{tabular}{|l|c|c|c|}
\hline & $\eta_{\mathbf{0}}[\mathbf{P a} \cdot \mathbf{s}]$ & $\mathbf{k}[\mathbf{s}]$ & $\mathbf{m}$ \\
\hline E32-0X & 2321 & 0.016 & 0.86 \\
\hline E32-3X & 3163 & 0.019 & 0.78 \\
\hline
\end{tabular}

The results above mentioned indicate that some changes in the chain structure, induced during the processing of $\mathrm{EVOH}$, altered the rheological behaviour, increasing the overall viscosity of the melt under similar temperature and shear conditions. Such behaviour supports the idea of an increase in molecular weight $\left(M_{w}\right)$ altogether with a slight increase on molecular weight distribution. Artzi et al. [19] working with EVOH/nanocomposites pointed out that when EVOH is processed at high temperatures, two competitive mechanisms may take place, namely thermal degradation (with chain scission) and grafting and oxidative crosslinking reactions. Similar results have been reported by Lagaron et al. [20] under thermo-oxidative conditions (about $2 \mathrm{~h}$ at $215^{\circ} \mathrm{C}$ ) without shearing.

Considering that some traces of acetoxyl groups from incomplete saponification of EVA precursor could be present, some intermolecular transesterification reactions between the ester and hydroxyl groups could be taking place, resulting in some cross-linking and/or chain extension reactions. In addition, Rodríguez-Vázquez et al. [21] suggested some combination and addition of macro-radicals to chain-linked double bonds studying degradation and stabilization of EVA, which could also be present in $\mathrm{EVOH}$.
The increase on shear viscosity in the Newtonian plateau implies an increase in the elongational viscosity (following the Troutonian relation), which would promote an increase on the orientation degree during calendering [22]. Consequently, it can be expected to find out other changes in the film properties like in the mechanical behaviour [12].

\subsection{Dynamic mechanical thermal analysis}

The DMTA analysis performed in tensile mode revealed the differences in the mechanical behaviour of the films after reprocessing. This is shown in Figure 3, where the storage modulus and loss tangent $(\tan \delta)$ of E32-0X and E32-3X are presented.

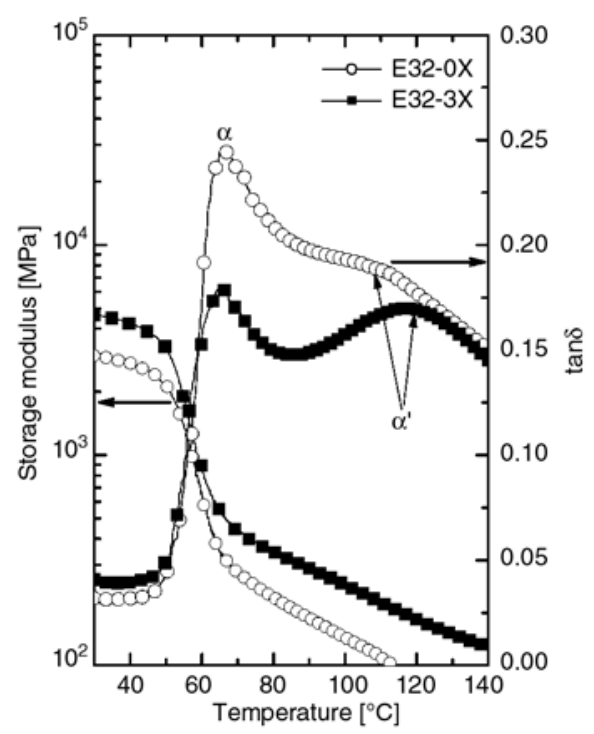

Figure 3. Temperature dependence of the storage modulus and loss tangent of $\mathrm{EVOH}$ 
It can be observed that the storage modulus increased after the three twin-screw extruder steps in the whole range of temperatures evaluated. On the other hand, it is also noticeable that $\tan \delta$ shows two maxima, indicating different structural relaxations. The main one, labelled as $\alpha$ in Figure 3 is indicative of glass transition temperature and remains unchanged at approximately $63^{\circ} \mathrm{C}$. The lower intensity of this signal in the E32-3X film is consequence of a decrease on the viscous component (loss modulus) along with the mentioned raise in storage modulus.

The second relaxation phenomenon, named as $\alpha^{\prime}$ is displayed at about $110-120^{\circ} \mathrm{C}$. It is quite noticeable the increase in the definition and shift to higher temperatures for E32-3X. According to Cerrada et al. [23], $\alpha^{\prime}$ is strongly related to the molecular orientation, corresponding to motions within the crystalline phase, caused either by the relaxation of hydrogen bonds or the movements close to the crystal lamellae surface. In this case, such orientation could have been induced during the cast film processing.

Since cast-film processing conditions were exactly the same in all cases, the fact that the film E32-3X shows higher orientation can be explained on basis of the increase of viscosity produced by the twinscrew extruder reprocessing. Such orientation, along with the hypothetical increase on $M_{w}$ and/or cross-linking, would be the cause for the higher values on storage modulus upon reprocessing on twin-screw extruder.

\subsection{Differential scanning calorimetry}

In Figure 4 are shown the DSC melting endotherms corresponding to the first and the second heating scans for all films. The thermal parameters obtained are summarized in Table 2.

In the first heating scan (Figure 4a) it can be observed that the endothermic signal becomes more intense and slightly narrower as the number of twin-screw extrusion steps increases, indicating that the most homogeneous crystal distribution is found in the E32-3X film. Concerning to the second heating scan, the intensity of the DSC melting endotherms does not evidence significant variations as the number of twin-screw extrusion steps increase, as seen in Figure 4b. Therefore, it can be deduced that the first heating scan, which is affected by the thermo-mechanical history of the films, is strongly influenced by the induced morphology of the films during the cast-film process (crystallization in oriented melt). This is also evidenced on the $X_{c}$ values (shown in Table 2) during the first melting, which are larger than those obtained from the DSC curves recorded during second heating run.

Table 2. Melting temperatures and crystallization degree of EVOH copolymers films

\begin{tabular}{|l|c|c|c|c|}
\hline \multirow{2}{*}{} & \multicolumn{2}{|c|}{ First heating } & \multicolumn{2}{c|}{ Second heating } \\
\cline { 2 - 5 } & $\mathbf{T}_{\mathbf{m}}\left[{ }^{\circ} \mathbf{C}\right]$ & $\mathbf{X}_{\mathbf{c}}[\mathbf{\%}]$ & $\mathbf{T}_{\mathbf{m}}\left[{ }^{\circ} \mathbf{C}\right]$ & $\mathbf{X}_{\mathbf{c}}[\mathbf{\%}]$ \\
\hline E32-0X & 182.1 & 67 & 183.3 & 47 \\
\hline E32-1X & 181.1 & 61 & 182.1 & 48 \\
\hline E32-2X & 180.7 & 61 & 182.2 & 46 \\
\hline E32-3X & 178.4 & 57 & 181.4 & 40 \\
\hline
\end{tabular}
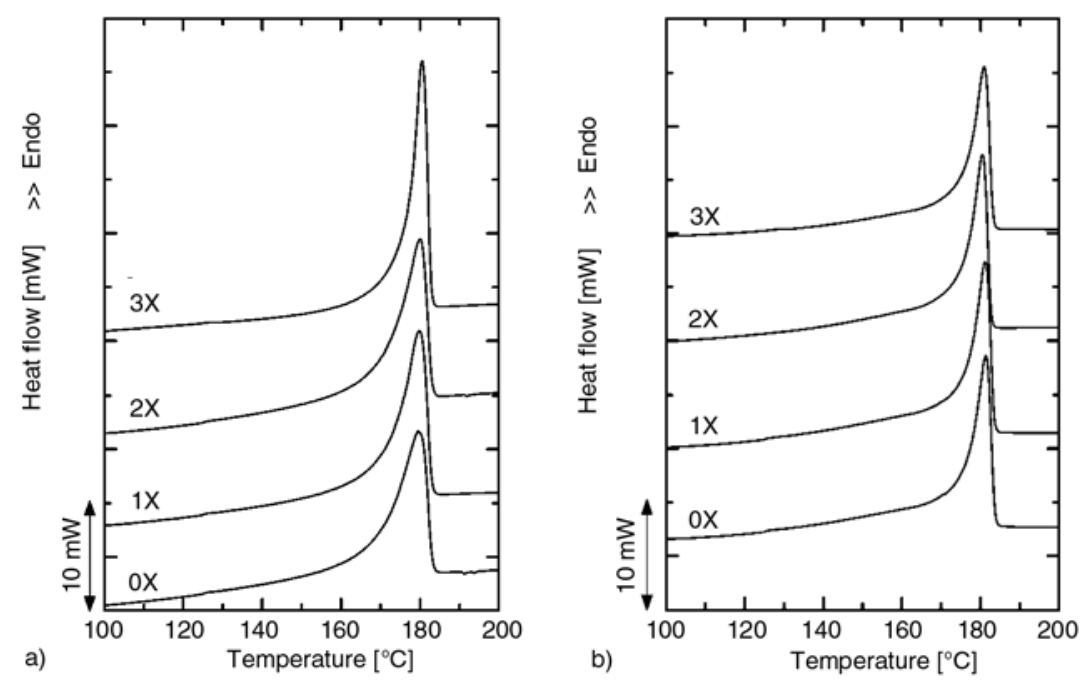

Figure 4. DSC heating scan: a) first heating and b) second heating after controlled cooling 
Table 2 summarizes the assessed thermal parameters in the first and second heating scans. It can be noticed that during the first heating scan, the crystal melting temperature of the reprocessed films, especially in the case of E32-3X, are slightly lower than those shown by the E32-0X film. On the other hand, during the second scan, the melting temperature $\left(T_{m}\right)$ of EVOH seems not to be affected by the twin-screw reprocessing. This data would be in agreement with the processing induced orientation of the E32-3X films, previously stated.

Concerning the variations in the crystallinity percentage, a decreasing trend with the number of reprocessing steps can be observed in Table 2 . Such trend would imply that under the dynamic cooling conditions applied, the crystallization ability of the reprocessed materials is hindered. Again, these results point to some structural modification, like some cross-linking, that could be taking place and affecting the crystallization process.

\subsection{Successive self-nucleation and annealing (SSA)}

Figure 5 shows the final heating scans after applying the SSA thermal treatment (i.e., the final heating run in the experimental part, ramp B in Figure 1). It can be appreciated a great segregation with outstanding resolution of the melting signals, similar to those obtained for LDPE and LLDPE systems. This segregation should be expected if the existence of short chain branching is considered. According to Vanderhart et al. [4] in their work about molecular partitioning on EVOH monitored

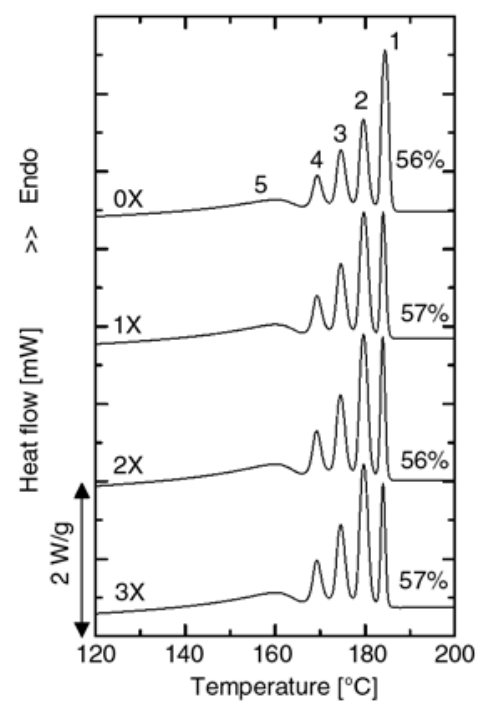

Figure 5. DSC heating scans after SSA fractionation by solid-state ${ }^{13} \mathrm{C}$, while $\mathrm{OH}$ group behaves like an interstitial defects, short chain branches of one, two and four carbons, as well as acetate branches are strongly rejected form the crystalline region of these copolymers, just like in LDPE [16].

The SSA treatment produced five fractions in every sample. Only those four $T_{s}$ temperatures capable of producing self-nucleation and annealing are considered for the analysis, since they are directly responsible for the annealed crystals that subsequently melt during final heating scan. Figure 6 shows the melting temperature of each fraction $v s$. $T_{s}$. It can be seen that, as expected, these melting temperatures only depend on the $T_{s}$ temperature. This indicates that the fractionation procedure is effective in separating chains of a particular short chain branching content.

The DSC curves of Figure 5 can be integrated and partial areas corresponding to each peak. They can be considered to be proportional to a normalised weight fraction of crystalline population with same lamellar thickness. The histogram associated to the enthalpy fractions is shown in Figure 7. It is possible to observe a great depletion of the most linear fraction when EVOH copolymer is processed by twin-screw extruder. This reduction contrasts to the behaviour displayed by less linear one, with $T_{s}$ temperatures of 179,174 and $169^{\circ} \mathrm{C}$, which tend to increase at the expense of the highest one $\left(T_{s}=\right.$ $\left.184^{\circ} \mathrm{C}\right)$. Similar behaviour has been observed by Marquez et al. [17] on LLDPE grafted with diethyl maleate (DEM), where the most linear sequences showed the higher susceptibility to the DEM attack.

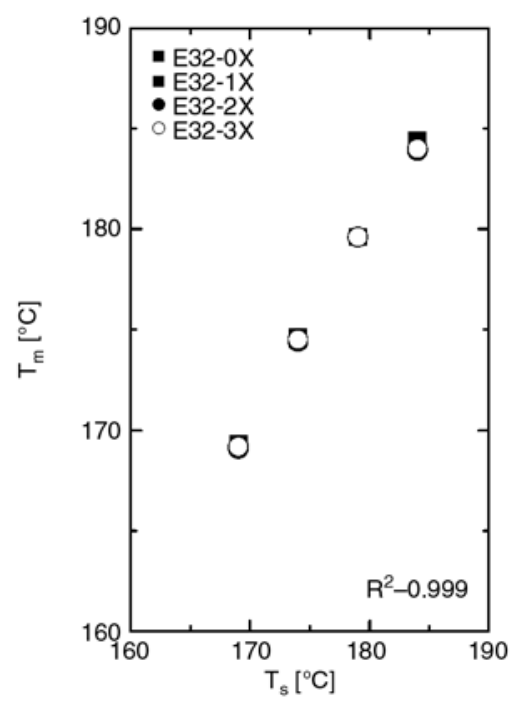

Figure 6. Linear relationship between the melting peak and $T_{S}$ temperatures 


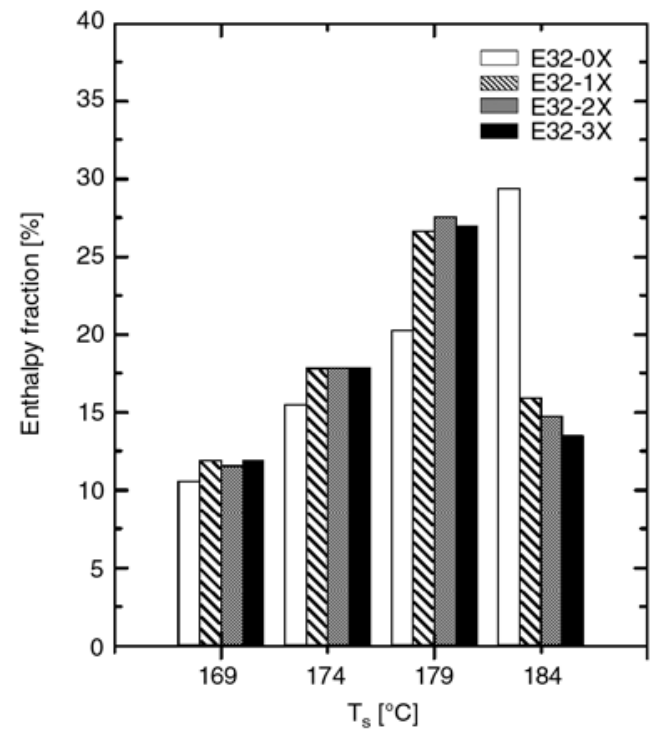

Figure 7. Histogram corresponding to the enthalpy fraction contribution

In our case, the above mentioned depletion could be a consequence of the reactions occurred during the twin-screw extrusion, as discussed previously; pointing out that the strongest variation seems to occur after the first twin-screw extrusion process. It is interesting to note that the crystallinity degree generated after the SSA treatment in all sample remains constant $(\approx 56 \%$ ) (as reported in Figure 5), what seems to indicate that the chemical modifications affect to the crystallization characteristics under dynamic conditions (kinetic aspects). But if the experimental conditions favour an annealing or the thermal rates are slow, the material has basically the same crystallization ability.

\section{Conclusions}

The melt-blending process of EVOH copolymers induces some structural modifications, which promoted a high molecular orientation of the films during the cast-film process.

MFR and rheological measurements displayed an increase on molecular weight of EVOH as a consequence of chain-extension reactions promoted by the reactivity of residual hydroxyl and acetoxyl groups. According to the DMTA results, the reactions should improve the mechanical behaviour, as appreciated by high storage modulus obtained.

The thermal fractionated EVOH films clearly showed a great segregation of several series of melting signals, proving that the SSA technique is a complementary useful tool for the structural char- acterization. The modifications induced during the processing of EVOH promoted the redistribution of the crystalline populations, where the less linear fractions were favoured by the most linear one.

\section{Acknowledgements}

The authors want to thank to the Ministerio de Educación y Ciencia for the financing of the MAT 2003-08480-C03-02 project. E. Franco-Urquiza thanks to the National Council of Science and Technology (CONACyT) of México, for the support of a doctoral research grant.

\section{References}

[1] Noro K.: Hydrolisis of polyvinyl acetate to polyvinyl alcohol. in 'Polyvinyl alcohol: Properties and applications' (ed.: Finch C. A.) John Wiley, London, Vol 1, 91-120 (1973).

[2] Pérez E., Lujan M., de Salazar J. M.: Preparation and properties of terpolymers of ethylene, vinyl acetate and vinyl alcohol. Macromolecular Chemistry and Physics, 201, 1323-1328 (2000).

DOI: $10.1002 / 1521-3935(20000801) 201: 12<1323:$ : AID-MACP1323>3.0.CO;2-7

[3] Ramakrishnan S.: Well-defined ethylene vinyl alcohol copolymers via hydroboration- control of composition and distribution of the hydroxyl-groups on the polymer backbone. Macromolecules, 24, 3753-3759 (1991).

DOI: $\underline{10.1021 / \mathrm{ma} 00013 \mathrm{a} 003}$

[4] Vanderhart D. L., Simmons S., Gilman J. W.: Solidstate C-13 nuclear-magnetic-resonance spectroscopy of ethylene-vinyl alcohol copolymers - Morphological partitioning of hydroxyls. Polymer, 36, 4223-4232 (1995).

DOI: $10.1016 / 0032-3861(95) 92217-3$

[5] Lasagabaster A., Abad M. J., Barral L., Ares A.: FTIR study on the nature of water sorbed in polypropylene (PP)/ethylene alcohol vinyl (EVOH) films. European Polymer Journal, 42, 3121-3132 (2006).

DOI: 10.1016/j.eurpolymj.2006.03.029

[6] Aucejo S., Marco C., Gavara R.: Water effect on the morphology of EVOH copolymers. Journal of Applied Polymer Science, 74, 1201-1206 (1999). DOI: 10.1002/(SICI) 1097-4628(19991031)74:5 $\leq 1201:$ AID-APP17>3.0.CO;2-8

[7] Alvarez V. A., Ruseckaite V. A., Vázquez A.: Kinetic analysis of thermal degradation in poly(ethylene-vinyl alcohol) copolymers. Journal of Applied Polymer Science, 90, 3157-3163 (2003).

DOI: $10.1002 / a p p .13071$

[8] Cerrada M. L., Pérez E., Pereña J. M., Benavente R.: Wide-angle X-ray diffraction study of the phase behavior of vinyl alcohol and ethylene copolymers. Macromolecules, 31, 2559-2564 (1998).

DOI: $\underline{10.1021 / \mathrm{ma} 9705127}$ 
[9] Artzi N., Narkis M., Siegmann A.: EVOH/clay nanocomposites produced by dynamic melt mixing. Polymer Engineering and Science, 44, 1019-1026 (2004).

DOI: $10.1002 /$ pen.20095

[10] Artzi N., Khatua B. B., Tchoudakov R., Narkis M., Berner A., Siegmann A., Lagaron J. M.: Physical and chemical interactions in melt mixed Nylon-6/EVOH blends. Journal of Macromolecular Science Part B: Physics, 43, 605-624 (2005).

DOI: $\underline{10.1081 / \mathrm{MB}-120030009}$

[11] Chow W. S., Khim L. Y., Kang A. T.: Flexural properties of polystyrene/organo-montmorillonite masterbatch composites. Journal of Reinforced Plastics and Composites, 27, 255-261 (2008). DOI: $10.1177 / 0731684407083001$

[12] Franco-Urquiza E., Gamez-Perez J., Sánchez-Soto M., Santana O. O., Maspoch M. L.: The effect of organomodifier on structure and properties of poly(ethylenevynil alcohol)/organo-modified montmorillonite composites. Polymer International, in press (2010). DOI: $10.1002 /$ pi.2788

[13] Maspoch M. L., Franco-Urquiza E., Gamez-Perez J., Santana O. O., Sanchez-Soto M.: Fracture behaviour of poly[ethylene-(vinyl alcohol)]/organo-clay composites. Polymer International, 58, 648-655 (2009). DOI: $10.1002 /$ pi.2574

[14] Müller A., Hernández Z., Arnal M., Sánchez J.: Successive self-nucleation/annealing (SSA): A novel technique to study molecular segregation during crystallization. Polymer Bulletin 39, 465-472 (1997). DOI: $10.1007 / \mathrm{s} 002890050174$

[15] Arnal M., Balsamo V., Ronca G., Sánchez A., Müller A., Cañizales E., de Navarro C.: Applications of successive self-nucleation and annealing (SSA) to polymer characterization. Journal of Thermal Analysis and Calorimetry, 59, 451-470 (2000). DOI: 10.1023/A:1010137408023

[16] Müller A. J., Arnal M. L.: Thermal fractionation of polymers. Progress in Polymer Science 30, 559-603 (2005).

DOI: $10.1016 / j . p r o g p o l y m s c i .2005 .03 .001$
[17] Marquez L., Rivero I., Müller A.: Application of the SSA calorimetric technique to characterize LLDPE grafted with diethyl maleate. Macromolecular Chemistry and Physics, 200, 330-337 (1999).

DOI: 10.1002/(SICI)1521-3935(19990201)200:2 $\leq 330::$ AID-MACP330>3.0.CO;2-Y

[18] Fillon B., Wittmann J. C., Lotz B., Thierry A.: Selfnucleation and recrystallization of isotactic polypropylene (alpha phase) investigated by differential scanning calorimetry. Journal of Polymer Science Part B: Polymer Physics, 31, 1383-1393 (1993).

DOI: $10.1002 /$ polb.1993.090311013

[19] Artzi N., Tzur A., Narkis M., Siegmann A.: The effect of extrusion processing conditions on EVOH/clay nanocomposites at low organo-clay contents. Polymer Composites, 26, 343-351 (2005).

DOI: $\underline{10.1002 / p c .20096}$

[20] Lagaron J. M., Giménez E., Saura J. J.: Degradation of high barrier ethylene-vinyl alcohol copolymer under mild thermal-oxidative conditions studied by thermal analysis and infrared spectroscopy. Polymer International, 50, 635-642 (2001).

DOI: $10.1002 /$ pi.674

[21] Rodriguez-Vazquez M., Liauw C. M., Allen N. S., Edge M., Fontan E.: Degradation and stabilisation of poly(ethylene-stat-vinyl acetate): 1-spectroscopic and rheological examination of thermal and thermo-oxidative degradation mechanisms. Polymer Degradation and Stability, 91, 154-164 (2006).

DOI: $10.1016 /$ j.polymdegradstab.2005.04.034

[22] Wissbrun K., Dealy J. M.: Melt rheology and its role in plastics processing: Theory and applications. Kluwer Academics, Dordrecht (1990).

[23] Cerrada M. L., Benavente R., Pérez E., Pereña J. M.: The effect of tensile drawing on the structure and relaxation processes in vinyl alcohol-ethylene copolymers. Polymer, 42, 3127-3138 (2001). DOI: $\underline{10.1016 / \mathrm{S} 0032-3861(00) 00698-4}$ 